Int. J. Dev. Biol. 49: 867-871 (2005)

doi: $10.1387 / \mathrm{ijdb} .052016 \mathrm{hm}$

Original Article

\title{
Cdx2 specifies the differentiation of morphological as well as functional absorptive enterocytes of the small intestine
}

\author{
HIROYUKI MUTOH*, KIICHI SATOH, HIROTO KITA, HIROTSUGU SAKAMOTO, HIROKO HAYAKAWA, \\ HIRONORI YAMAMOTO, NORIO ISODA, KIICHI TAMADA, KENICHI IDO and KENTARO SUGANO \\ Department of Gastroenterology, Jichi Medical School, Tochigi, Japan
}

\begin{abstract}
Many transcription factors are involved in the molecular control of intestinal epithelial cell differentiation. We report in this study that the transcription factor Cdx 2 functions to define absorptive enterocytes during intestinal epithelial differentiation. Cdx 2 is expressed in the villi of the normal small intestine. Intestinal metaplasia, which expresses $\mathrm{Cdx2}$, occurs as a pathological condition in gastric mucosa. We have previously established Cdx2 transgenic mice expressing Cdx2 exclusively in the gastric epithelium. In this study using $\mathrm{Cdx} 2$ transgenic mice, we show that $\mathrm{Cdx} 2$ plays a key role in the differentiation of intestinal absorptive enterocytes. The gastric mucosa of Cdx2 transgenic mice was morphologically completely changed into intestinal metaplastic mucosa. Absorptive enterocytes had microvilli which were observed by electron microscope. The intestinal metaplastic mucosa of Cdx2 transgenic mice expressed sucrase and peptide transporter PepT1. Disaccharidase and leucine aminopeptidase activities were observed in the intestinal metaplastic mucosa. Glucose and amino acids were absorbed from Cdx2 transgenic mouse stomach with intestinal metaplasia. Finally we generated mice whose intestine was extensively excised. Cdx2 transgenic mice with intestinal metaplasia survived even after extensive intestinal excision. We successfully demonstrated that $\mathrm{Cdx} 2$ induced not only morphological but also functional absorptive enterocytes in the intestinal metaplastic mucosa in vivo. Our results suggest that $\mathbf{C d x} 2$ is necessary and sufficient by itself to specify the development of intestinal absorptive enterocytes, whereas other factors which are expressed in the small intestine are not always necessary for the differentiation of functional absorptive enterocytes.
\end{abstract}

KEY WORDS: Cdx2, absorptive enterocyte, transgenic mouse

\section{Introduction}

Cdx2, caudal-related homeobox transcription factor, is selectively localized in the fetal and adult mucosal epithelial nuclei of small and large intestine in both humans and mice (Meyer and Gruss, 1993). Cdx2 is important in the transcriptional regulation of intestinal genes and the differentiation of intestinal cells in vitro (Suh et al., 1994) (Suh and Traber, 1996). Inactivation of Cdx2 by homologous recombination results in the development of multiple intestinal polyp-like lesions in pericaecal areas of the midgut of heterozygote mice (Beck et al., 2003). These polyps did not express $\mathrm{Cdx} 2$ and consisted of hamartoma containing areas which are similar to keratinizing stratified squamous epithelium found in the mouse forestomach, columnar mucous-secreting cells found in the gastric cardia and parietal cells found in the gastric corpus.

In the progression of chronic gastritis, gastric mucosal cells deviate from the normal pathway of gastric differentiation to an intestinal phenotype. Helicobacter pylori infection is involved in the process of progression from normal gastric mucosa to superficial gastritis, chronic active gastritis, atrophic gastritis and finally to intestinal metaplasia (Correa, 1992). We and others have reported that intestine-specific transcription factor $\mathrm{Cdx} 2$ is expressed in human gastric intestinal metaplastic mucosa (Eda et al., 2002) (Satoh et al., 2002) (Almeida et al., 2003) (Bai et al., 2002) (Mizoshita et al., 2001). Furthermore, we established Cdx2 transgenic mice that expressed $\mathrm{Cdx} 2$ exclusively in the gastric epithelium (Mutoh et al., 2002). The gastric fundic mucosa of Cdx2 transgenic mice was morphologically completely changed into intestinal metaplastic mucosa. These metaplastic glands were composed of a large number of goblet cells, columnar

Abbreviations used in this paper: BCAA, branched-chain amino acid; PepT, peptide transporter.

\footnotetext{
*Address correspondence to: Dr. Hiroyuki Mutoh. Department of Gastroenterology, Jichi Medical School, Yakushiji 3311-1, Minamikawachimachi, Kawachigun, Tochigi 329-0498, Japan. Fax: +81-285-44-8297. e-mail: muto@jichi.ac.jp
} 

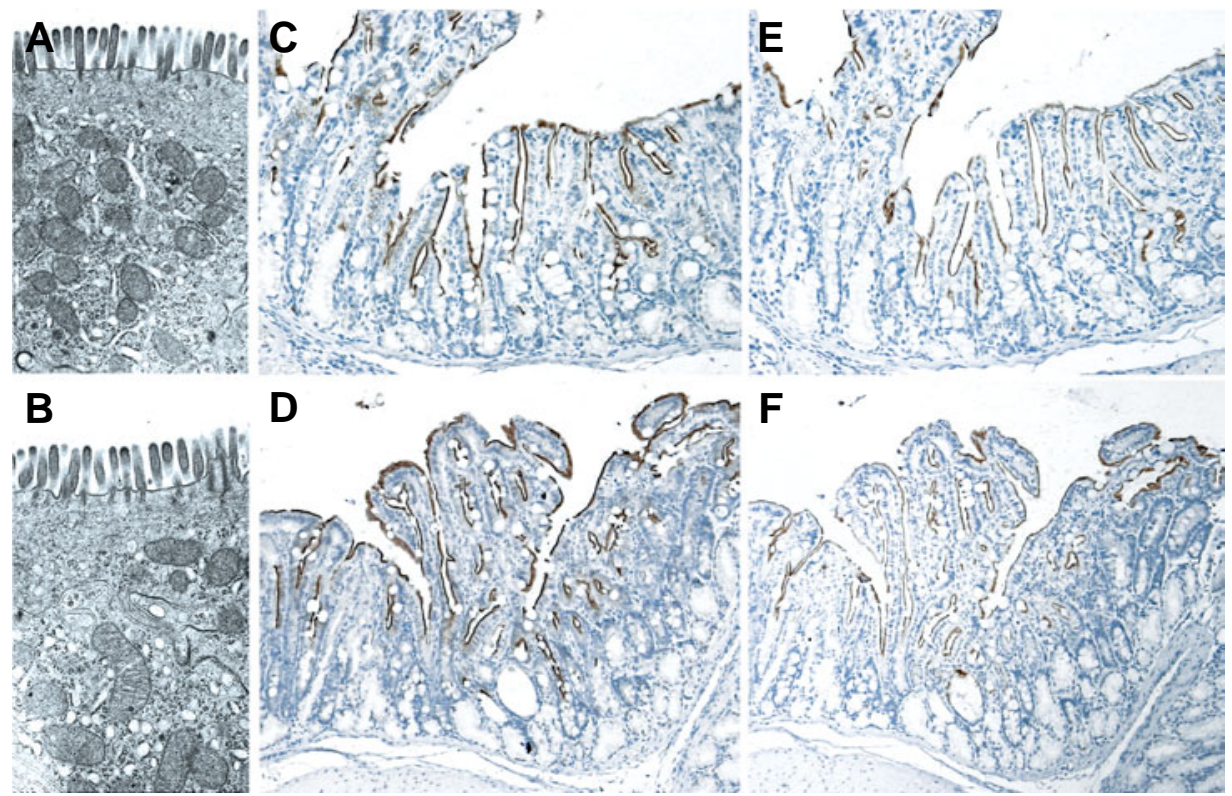

D $\quad$ c
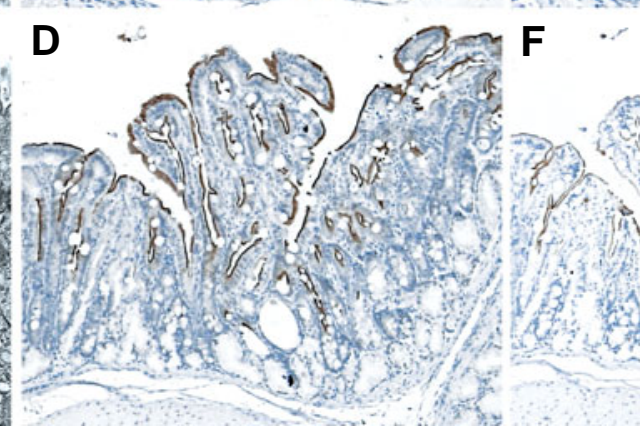

$F$

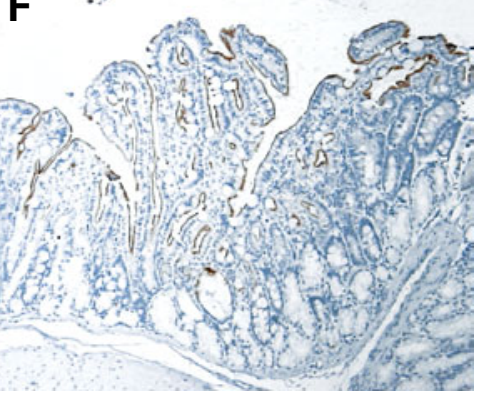

Fig. 1. Absorptive enterocytes. Microvilli (A: 37 days after birth, B: 244 days after birth), sucrase (C: 37 days after birth, D: 244 days after birth) and peptide transporter (PepT1) (E: 37 days after birth, F: 244 days after birth) in intestinal metaplastic mucosa of the Cdx2 transgenic mouse stomach. (A,B) Electron microscopy revealed microvillion the luminal surface of absorptive enterocytes. (C,D) Sucrase immunoreactivity was observed, which was widely distributed on the luminal surface of intestinal metaplastic epithelial cells. (E,F) PepT1 immunoreactivity was also widely found on the luminal surface of intestinal metaplastic epithelial cells.

intestinal-type epithelial cells and enteroendocrine cells. We evaluated the features of absorptive enterocytes by brush border and alkaline phosphatase activity in the surface of columnar intestinal-type epithelial cells. Currently, it has not been elucidated whether $\mathrm{Cdx} 2$ can differentiate absorptive enterocytes with absorptive function. The $\mathrm{Cdx} 2$ transgenic mouse is a good model for clarifying whether $\mathrm{Cdx} 2$ can differentiate morphological as well as functional absorptive enterocytes in vivo.

Findings from the intestinal metaplasia of $\mathrm{Cdx} 2$ transgenic mouse stomach and the intestinal polyps of heterozygous $\mathrm{Cdx} 2$ knockout mice suggest that $\mathrm{Cdx} 2$ might play a key role in intestinal epithelial cell fate determination and differentiation. These findings prompted us to investigate whether $\mathrm{Cdx} 2$ is able to differentiate absorptive enterocytes with enzymatic and absorptive functions in vivo. We successfully demonstrated that $\mathrm{Cdx} 2$ induced not only morphological but also functional absorptive enterocytes in intestinal metaplastic mucosa in vivo. The present results suggest that $\mathrm{Cdx} 2$ is necessary and is sufficient by itself to specify the development of intestinal absorptive enterocytes, whereas other factors that are expressed in the small intestine are not always necessary for the differentiation of functional absorptive enterocytes.

\section{Results}

We had previously established $\mathrm{Cd} 2 \mathrm{2}$ transgenic mice expressing Cdx2 exclusively in gastric epithelium (Mutoh et al., 2002). The gastric mucosa of $\mathrm{Cdx} 2$ transgenic mice was morphologically completely changed into intestinal metaplastic mucosa. In order to better characterize the intestinal metaplasia induced by $\mathrm{Cdx} 2$, we examined whether Cdx2 can induce the enterocytes with intestinal absorptive function in addition to morphological intestinal metaplasia in the $\mathrm{Cdx} 2$-transgenic mice.

Electron microscopy revealed microvilli on the luminal surface of absorptive enterocytes (Fig. $1 \mathrm{~A}, \mathrm{~B}$ ). The sections were stained by the antibodies for sucrase and peptide transporter PepT1 (Fei et al., 1994) in order to characterize the intestinal metaplasia. Sucrase and PepT1 were strongly and widely expressed on the luminal surface of the intestinal metaplastic mucosal epithelial cells (Fig. 1 CF).

To clarify whether disaccharides are actually digested because sucrase was detected by immunohistochemistry, disaccharides (sucrose, maltose, trehalose) were incubated at $37^{\circ} \mathrm{C}$ for $60 \mathrm{~min}$ with homogenized mucosa of normal stomach, intestinal metaplasia and normal small intestine. Glucose concentrations derived from digested disaccharides (sucrose, maltose, trehalose) increased in the incubations with homogenized mucosa of both small intestine and intestinal metaplasia (Table 1). The glucose concentration in homogenized mucosa of intestinal metaplasia was almost equal to that of normal small intestine, whereas the glucose concentration did not increase in homogenized gastric mucosa (Table 1). The finding that Cdx2-induced intestinal metaplastic mucosa is able to digest disaccharides indicates that sucrase, maltase and trehalase are functionally active.

We then examined whether the glucose derived from the digestion of these disaccharides is absorbed by intestinal metaplastic mucosa. Serum glucose concentrations in Cdx2 transgenic mice increased after $0.5 \mathrm{ml}$ of $50 \%$ glucose was administered into the stomach with ligated cardia and pylorus. However, glucose concentrations in normal mice did not increase after glucose administration into the stomach (Fig. 2).

To examine whether there is any activity for digesting peptides in the intestinal metaplastic mucosa, we measured leucine aminopeptidase activity in normal gastric mucosa, intestinal metaplastic mucosa and normal intestinal mucosa. Leucine aminopeptidase activity was found in homogenized intestinal metaplastic mucosa and normal intestine, whereas it was not detected in

TABLE 1

\section{SUCRASE, MALTASE AND TREHALASE ACTIVITIES IN THE NORMAL STOMACH AND SMALL INTESTINE AND INTESTINAL METAPLASTIC MUCOSA}

\begin{tabular}{lccc} 
& Normal stomach $(\mathbf{m g} / \mathbf{d L})$ & intestinal metaplasia(mg/dL) & small intestine $(\mathbf{m g} / \mathbf{d L})$ \\
\hline sucrose & $1 \pm 0$ & $115 \pm 10$ & $138 \pm 7$ \\
maltose & $25 \pm 1$ & $643 \pm 30$ & $566 \pm 41$ \\
trehalose & $1 \pm 0$ & $120 \pm 5$ & $201 \pm 30$ \\
\hline
\end{tabular}

Values are means \pm SE. 

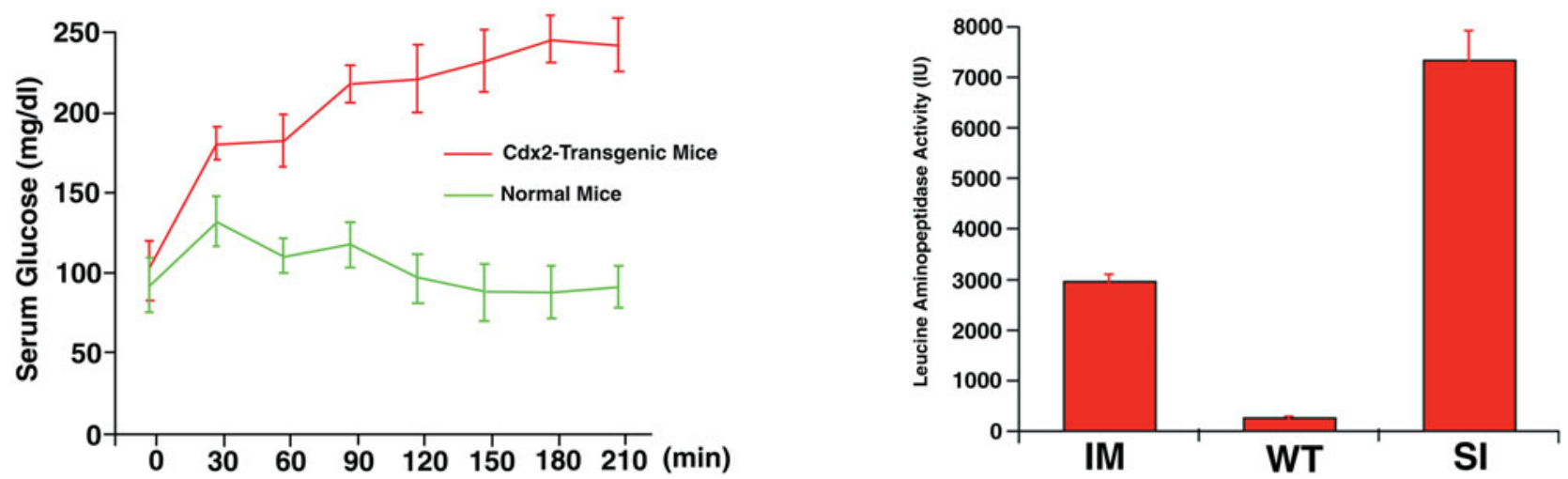

Fig. 2 (Left). Absorption of glucose. Serum glucose levels increased after $0.5 \mathrm{ml}$ of $50 \%$ glucose was administered into Cdx 2 transgenic mouse stomach with ligation of the cardia and pylorus, whereas glucose concentrations in the normal ligated mouse stomach did not increase. Ten wild-type and $10 \mathrm{Cd} 22$ transgenic mice (120 days old) were used. Data are expressed as mean \pm SD.

Fig. 3 (Right). Leucine aminopeptidase activity in intestinal metaplastic mucosa (IM), normal gastric mucosa (WT) and normal small intestinal mucosa (SI). Leucine aminopeptidase activity in intestinal metaplastic mucosa and normal small intestinal mucosa was observed, whereas it was not detected in normal gastric mucosa. Ten intestinal metaplastic mucosas, 10 normal gastric mucosas and 10 Cdx2 transgenic mouse gastric mucosas (120 days old) were used. Data are expressed as mean $\pm S D$.

homogenized normal gastric mucosa (Fig. 3).

We also determined whether amino acids derived from digestion of the peptides are absorbed by intestinal metaplastic mucosa. Amino acids (valine, leucine, isoleucine, tyrosine) were administered into normal and $\mathrm{Cdx} 2$ transgenic mouse stomach with ligated cardia and pylorus. The levels of tyrosine and branched-
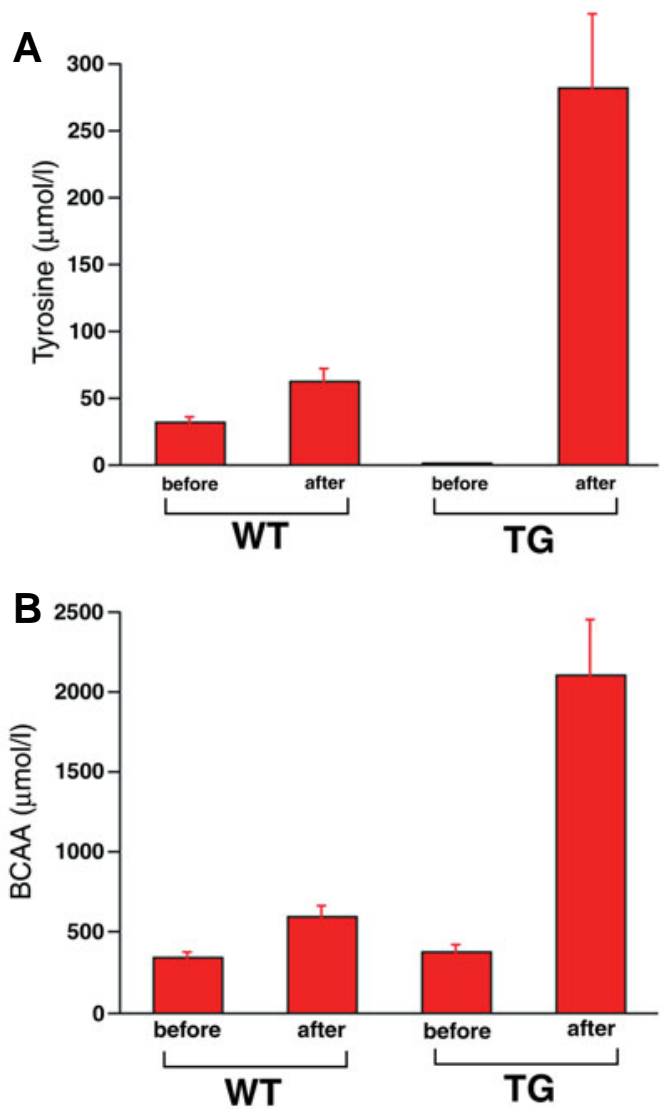

chain amino acids in the serum increased after amino acid administration, while they did not increase in normal mouse stomach (Fig. 4). The results show that the intestinal metaplastic mucosa has both enzymatic and absorptive functions and indicate that $\mathrm{Cdx} 2$ transgenic mice might be able to survive without small intestine.

We then generated mice whose small intestine was extensively excised. Cdx2 transgenic mice with intestinal metaplasia survived more than 1 month after intestinal excision (Fig. 5). On the other hand, normal mice had rapid weight loss after the operation and died within 7 days (Fig. 5).

\section{Discussion}

The morphological intestinal metaplastic mucosa induced by transcription factor $\mathrm{Cdx} 2$ in the stomach had enzymatic and absorptive function specific to absorptive enterocytes in the small intestine. The present results suggest that $\mathrm{Cdx} 2$ is a key regulator for the development and differentiation of absorptive enterocytes in small intestine in vivo. We determined that $\mathrm{Cdx} 2$ is necessary and sufficient by itself for this development and differentiation, whereas other factors that are expressed in the small intestine are not always necessary for the differentiation of functional absorptive enterocytes.

We have previously shown that Cdx2 transgenic mice developed normally into superficially healthy adults but showed intestinal metaplasia in the stomach up to 12 weeks of age (Mutoh et al., 2002). The gastric mucosa was completely replaced by

Fig. 4. Absorption of amino acids. The concentration of tyrosine (A) and branched-chain amino acids (BCAA) (B) in the serum increased after amino acids (valine, leucine, isoleucine, tyrosine) were administered into Cdx2 transgenic mouse stomach (TG) with ligation of the cardia and pylorus, while it did not increase in normal mouse stomach (WT). Ten wild-type and $10 \mathrm{Cd} \times 2$ transgenic mice (120 days old) were used. Data are expressed as mean $\pm S D$. 
intestinal metaplastic mucosa consisting of terminally differentiated intestinal epithelial cells. Hematoxylin and eosin-stained sections of the intestinal metaplastic mucosa of Cdx2 transgenic mouse stomach showed columnar intestinal-type epithelial cells in addition to a large number of goblet cells and enteroendocrine cells. Absorptive enterocytes are the most important for the intestinal epithelial cells because the main function of the small intestine is to digest food and absorb nutrients. Disaccharidase activities specific to absorptive enterocytes such as sucrase, maltase, trehalase and lactase were reported in human intestinal metaplastic mucosa, using specimens obtained by gastrectomy or endoscopic gastric biopsy (Classen et al., 1968) (Launiala and Siurala, 1968) (Capoferro, 1972) (Kawachi et al., 1974) (Gudmand-Hoyer et al., 1975). Cdx2 has been reported to regulate the expression of various genes specific to absorptive enterocytes in the intestine such as sucrase-isomaltase (Suh and Traber, 1996), lactase-phlorizin hydrolase (Troelsen et al., 1997), calbindinD9K (Colnot et al., 1998) and carbonic anhydrase I (Drummond

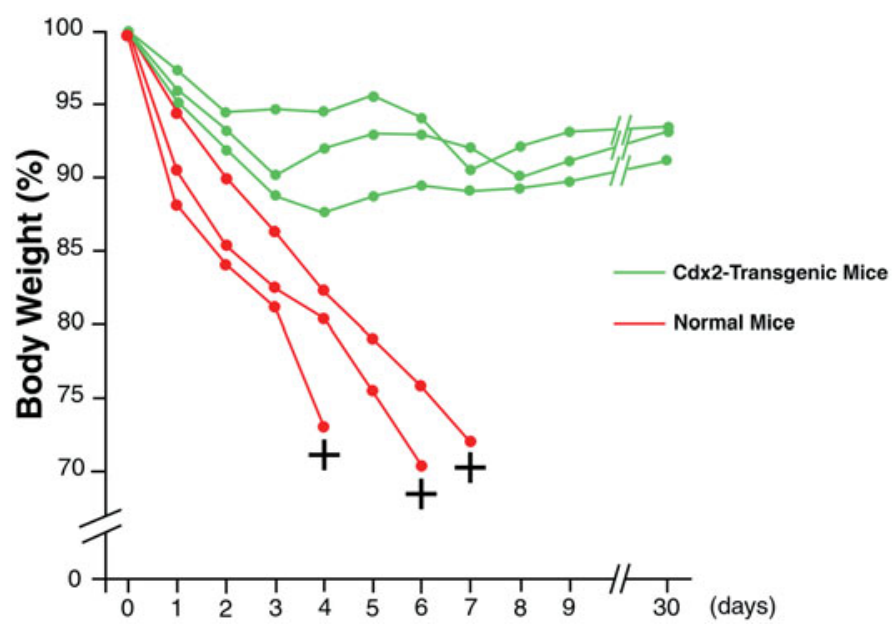

Fig. 5. Survival curve after extensive intestinal excision. The $C d x 2$ transgenic mice with intestinal metaplasia survived over 1 month after intestinal excision. On the other hand, the normal mice showed rapid weight loss after the operation and died within 7 days.

et al., 1998) in vitro, using the immature intestinal cell line, IEC6. Trans-differentiated epithelial cells in the gastric mucosa of Cdx2 transgenic mice have microvilli specific for intestinal absorptive enterocytes and express alkaline phosphatase, sucrase and peptide transporter (PepT1) extensively. These data suggest that $\mathrm{Cdx} 2$ might induce functional intestinal metaplastic mucosa. However, it has not been elucidated whether the absorptive enterocytes induced by $\mathrm{Cdx} 2$ have enzymatic and absorptive function characteristic of small intestinal mucosa in vivo.

Silberg et al. reported that transgenic mice expressing $\mathrm{Cdx} 2$ in gastric mucosa used cis-regulatory elements of Foxa3 ( $\mathrm{Hnf} 3 \gamma$ ) (Silberg et al., 2002). The Foxa3/Cdx2 transgenic mice induced intestinal metaplasia in the stomach. However, goblet cells were predominant and the presence of absorptive enterocytes was suggested only by alkaline phosphatase expression. Sucrase was not expressed in the Foxa3/Cdx2 transgenic mice.
Silberg et al., discussed that other factors specific to small intestine might be needed in addition to $\mathrm{Cdx} 2$ for the expression of sucrase. Forced expression of Cdx2 in IEC- 6 cells has been shown to induce cellular differentiation characterized by microvilli and sucrase-isomaltase gene expression (Suh and Traber, 1996). However, IEC-6 cells are of intestinal origin and might express other factors that cooperate with $\mathrm{Cdx} 2$ to induce mature enterocytes. In our study, the intestinal metaplastic mucosa of $\mathrm{Cdx} 2$ transgenic mice had absorptive and enzymatic functions characteristic of normal intestinal mucosa. The present results indicate that transcription factor $\mathrm{Cdx} 2$ is sufficient for inducing absorptive enterocytes without other intestine-specific factors and that $\mathrm{Cdx} 2$ is an important regulator for the development and differentiation of absorptive enterocytes in the gut. The results from $\mathrm{Cdx} 2$ transgenic mice substantiate that $\mathrm{Cdx} 2$ is a main transcription factor for inducing differentiation of not only morphological but also functional absorptive enterocytes in vivo.

Disaccharides and amino acids introduced into the stomach were digested and absorbed from the intestinal metaplastic mucosa. Cdx2 transgenic mice with functional intestinal metaplastic mucosa were able to survive even after extensive small bowel resection. The intestinal metaplastic mucosa with absorptive enterocytes is limited to the fundic region of the stomach. However, the pyloric ring might function as a valve and subsequently elongate the time for the nutrients to pass. Nutrients might be retained in the stomach with intestinal metaplastic mucosa and absorbed from the intestinal metaplastic mucosa due to the presence of the pyloric ring.

In conclusion, the absorptive enterocytes in $\mathrm{Cdx} 2$-induced intestinal metaplastic mucosa expressed enzymatic and absorptive functions, indicating that $\mathrm{Cdx} 2$ can induce not only morphological but also functional absorptive enterocytes. The present results suggest that $\mathrm{Cdx} 2$ plays an essential role for the differentiation of absorptive enterocytes during both intestinal ontogeny and continuous cell renewal in the mature organ.

\section{Materials and Methods}

\section{Cdx2 transgenic mice}

We used Cdx2 transgenic mice with stomach-specific expression of $\mathrm{Cdx} 2$ using the $\beta$-subunit gene promoter of rat $\mathrm{H}^{+} / \mathrm{K}^{+}$-ATPase (Mutoh et al., 2002). The gastric mucosa of $C d \times 2$ transgenic mice was completely changed to intestinal metaplastic mucosa (Mutoh et al., 2002).

\section{Immunohistochemistry}

Three-micron-thick sections were cut, deparaffinized, rehydrated in PBS, placed in $10 \mathrm{mmol} / \mathrm{L}$ citrate buffer $(\mathrm{pH} \mathrm{6.0)}$ ) and heated in an 850-W microwave for 10 minutes. Slides were preincubated with blocking buffer (Vector Laboratories, Burlingame, CA) for 15 minutes at room temperature. Primary antisera, anti-PepT1 (1:500, provided by Dr. K. Miyamoto) and anti-sucrase (1:500, provided by Dr. K. Miyamoto), were diluted in PBS and incubated overnight at $4^{\circ} \mathrm{C}$. Slides were then washed in PBS and incubated with Envision (DAKO, Tokyo, Japan). After development with 3, 3'-diaminobenzidine tetrahydrochloride (Vector Laboratories), slides were counterstained with hematoxylin and viewed under a light microscope.

\section{Fixation and preparation of tissue for electron microscopy}

Gastric intestinal metaplastic mucosa of $\mathrm{Cdx} 2$ transgenic mice was fixed at $4^{\circ} \mathrm{C}$ in $2 \%$ glutaraldehyde in PBS, followed by six washes in PBS 
with post fixation in $1 \%$ osmium tetroxide $\left(\mathrm{OsO}_{4}\right)$. They were examined by a HITACHI H-7500 scanning electron microscope.

\section{Digestion of disaccharides}

The gastric fundic mucosa and small intestinal mucosa of normal mice and the intestinal metaplastic mucosa of $\mathrm{Cdx} 2$ transgenic mice were excised and weighed. Following the addition of equal weight of normal saline, the excised specimens were homogenized for 30 seconds in a glass homogenizer in ice water. The homogenized tissues were incubated at $37^{\circ} \mathrm{C}$ for 1 hour with equal weight of each disaccharide solution $(0.1 \mathrm{M})$ (sucrose, maltose and trehalose). The disaccharidase activities were determined by measuring the concentrations of glucose derived from digested disaccharide. The concentration of glucose was determined by measuring the peroxide produced by the glucose oxidase reaction (Dahlqvist, 1961).

\section{Absorption of glucose and amino acids}

Ten wild-type and $10 \mathrm{Cdx} 2$ transgenic mice (120 days old) were denied access to food overnight and then anesthetized with ether. After the abdominal wall was incised, the cardia and the pylorus were ligated. Glucose or amino acids (valine, leucine, isoleucine, tyrosine) were administered into the stomach and the incision was sutured. Blood samples were then collected 1 hour after glucose or amino acid administration. Branched-chain amino acids (valine, leucine, isoleucine) and tyrosine were measured by an enzymatic method (Diacolor-BTR kit, Ono Pharm. Co., Osaka, Japan).

\section{Extensive small intestinal excision}

We generated mice whose intestine was extensively excised. The normal and Cdx2 transgenic mice (120 days old) were denied access to food overnight and then anesthetized with ether. After the abdominal wall was incised, the small intestine from the anal side of the duodenal papilla to $2 \mathrm{~cm}$ before the end of the ileum on the oral side was removed and the incision was sutured. The operated mice were maintained by feeding with an elemental diet (Elental; Ajinomoto Co., Tokyo, Japan) and the weight of each mouse was measured periodically.

\section{Acknowledgements}

This work was supported in part by Grants-in-Aid for Scientific Research (B) (13470122 for KS), Grants-in-Aid for Scientific Research (C) (14570501 forHM) and Grants-in-Aid for Exploratory Research(14657134 for KS) from the Japan Society for the Promotion of Science. We appreciate the expert technical assistance provided by $H$. Nagaki and $K$. Sasaki.

\section{References}

ALMEIDA, R., SILVA, E., SANTOS-SILVA, F., SILBERG, D.G., WANG, J., DE BOLOS, C. and DAVID, L. (2003). Expression of intestine-specific transcription factors, $c d x 1$ and $c d x 2$, in intestinal metaplasia and gastric carcinomas. JPathol 199: 36-40.

BAI, Y.Q., YAMAMOTO, H., AKIYAMA, Y., TANAKA, H., TAKIZAWA, T., KOIKE, M., KENJI YAGI, O., SAITOH, K., TAKESHITA, K., IWAI, T. etal. (2002). Ectopic expression of homeodomain protein $\mathrm{cd} \times 2$ in intestinal metaplasia and carcinomas of the stomach. Cancer Lett 176: 47-55.

BECK, F., CHAWENGSAKSOPHAK, K., LUCKETT, J., GIBLETT, S., TUCCI, J., BROWN, J., POULSOM, R., JEFFERY, R. and WRIGHT, N.A. (2003). A study of regional gut endoderm potency by analysis of cdx2 null mutant chimaeric mice. Dev Biol 255: 399-406.

CAPOFERRO, R. (1972). Intestinal metaplasia in experimental atrophic gastritis. Sucrase activity in the gastric mucosa of guinea-pigs after stomach irradiation. Scand J Gastroenterol 7: 711-2.
CLASSEN, M., VON HINUBER, G. and DEMLING, L. (1968). Disaccharidases of the gastric mucosa in chronic atrophic gastritis with intestinal metaplasia. Digestion 1: 52-8.

COLNOT, S., ROMAGNOLO, B., LAMBERT, M., CLUZEAUD, F., PORTEU, A., VANDEWALLE, A., THOMASSET, M., KAHN, A. and PERRET, C. (1998). Intestinal expression of the calbindin-d9k gene in transgenic mice. Requirement for a cdx2-binding site in a distal activator region. J Biol Chem 273: 31939-46.

CORREA, P. (1992). Human gastric carcinogenesis: A multistep and multifactorial process- first american cancer society award lecture on cancer epidemiology and prevention. Cancer Res 52: 6735-40.

DAHLQVIST, A. (1961). Determination of maltase and isomaltase activities with a glucose-oxidase reagent. Biochem $J$ 80: 547-51.

DRUMMOND, F.-J., SOWDEN, J., MORRISON, K. and EDWARDS, Y.H. (1998). Colon carbonic anhydrase i: Transactivation of gene expression by the homeodomain protein cdx2. FEBS Letters 423: 218-22.

EDA, A., OSAWA, H., YANAKA, I., SATOH, K., MUTOH, H., KIHIRA, K. and SUGANO, K. (2002). Expression of homeobox gene cdx2 precedes that of cdx1 during the progression of intestinal metaplasia. J Gastroenterol 37: 94-100.

FEI, Y.J., KANAI, Y., NUSSBERGER, S., GANAPATHY, V., LEIBACH, F.H., ROMERO, M.F., SINGH, S.K., BORON, W.F. and HEDIGER, M.A. (1994). Expression cloning of a mammalian proton-coupled oligonucleotide transporter. Nature 368: 565-5.

GUDMAND-HOYER, E., ASP, N.G. and MOLLMANN, K.M. (1975). Disaccharidase activities in intestinal metaplasia - contribution of lysosomal brush border enzymes. Scand J Gastroenterol 10: 653-6.

KAWACHI, T., KOGURE, K., TANAKA, N., TOKUNAGA, A. and SUGIMURA, T. (1974). Studies of intestinal metaplasia in the gastric mucosa by detection of disaccharidases with «tes-tape». J Nat/ Cancer Inst 53: 19-30.

LAUNIALA, K. and SIURALA, M. (1968). Disaccharidase activities of the atrophic gastric mucosa with intestinal metaplasia. Scand J Gastroentero/ 3: 160-2.

MEYER, B.I. and GRUSS, P. (1993). Mouse cdx-1 expression during gastrulation. Development 117: 191-203.

MIZOSHITA, T., INADA, K., TSUKAMOTO, T., KODERA, Y., YAMAMURA, Y., HIRAI, T., KATO, T., JOH, T., ITOH, M. and TATEMATSU, M. (2001). Expression of $c d x 1$ and $c d x 2$ mrnas and relevance of this expression to differentiation in human gastrointestinal mucosa - with special emphasis on participation in intestinal metaplasia of the human stomach. Gastric Cancer 4: 185-91.

MUTOH, H., HAKAMATA, Y., SATO, K., EDA, A., YANAKA, I., HONDA, S., OSAWA, H., KANEKO, Y. and SUGANO, K. (2002). Conversion of gastric mucosa to intestinal metaplasia in cdx2- expressing transgenic mice. Biochem Biophys Res Commun 294: 470-9.

SATOH, K., MUTOH, H., EDA, A., YANAKA, I., OSAWA, H., HONDA, S., KAWATA, H., KIHIRA, K. and SUGANO, K. (2002). Aberrant expression of cdx2 in the gastric mucosa with and without intestinal metaplasia: Effect of eradication of helicobacter pylori. Helicobacter 7: 192-8.

SILBERG, D.G., SULLIVAN, J., KANG, E., SWAIN, G.P., MOFFETT, J., SUND, N.J., SACKETT, S.D. and KAESTNER, K.H. (2002). Cdx2 ectopic expression induces gastric intestinal metaplasia in transgenic mice. Gastroenterology 122: 689-96.

SUH, E., CHEN, L., TAYLOR, J. and TRABER, P.G. (1994). A homeodomain protein related to caudal regulates intestine-specific gene transcription. $\mathrm{Mo} / \mathrm{Ce} / /$ Biol 14: 7340-51.

SUH, E. and TRABER, P.G. (1996). An intestine-specific homeobox gene regulates proliferation and differentiation. Mol Cel/ Biol 16: 619-25.

TROELSEN, J.T., MITCHELMORE, C., SPODSBERG, N., JENSEN, A.M., NOREN, O. and SJOSTROM, H. (1997). Regulation of lactase-phlorizin hydrolase gene expression by the caudal- related homoeodomain protein $\mathrm{cdx}-2$. Biochem $\mathrm{J}$ 322: 833-8.

Received: October 2004

Reviewed by Referees: November 2004 Modified by Authors and Accepted for Publication: April 2005 Edited by: Makoto Asashima 